\title{
Arsitektur High Tech pada Rancangan Gedung Futura Mega Electric Automobile di Surabaya
}

\author{
Afif Awayna ${ }^{1}$, Failasuf Herman Hendra ${ }^{2}$, Randy Pratama Salisnanda ${ }^{3}$ \\ 1,2,3 Jurusan Arsitektur, Fakultas Teknik Sipil dan Perencanaan, Institut Teknologi Adhi Tama Surabaya \\ Email: $\underline{\text { afifawayna1@gmail.com, }}, \underline{2}$ failasuf_herman@yahoo.com, ${ }^{3}$ ren.salisnanda87@ gmail.com
}

\begin{abstract}
Surabaya as metropolitan city needs solutions with problems related to air pollution. The use of electricity transportation is very necessary to replace conventional transportation that causes exhaust emissions and has a negative impact to the environment. Related to efforts to reduce emissions from transportation emissions, the Futura Mega Electric Automobile Building Design in Surabaya is a building design that functions of business, education and recreation facilities as a preparation to welcome future transportation technology advancements and as a first step to introduce the electric transportation technology are interesting idea. The building design process uses the High Tech Architecture theme approach that inspiration by the future of electric car buildings shape. Building architecture design is carried out through a series of stages starting from project identification, precedent studies, design programs, concepts to design development. The concept of Future Oriented macro was chosen based on the interrelationship between the title, the function of the building and the theme so that it is expected to be able to provide an image of the building which is oriented towards the future, in harmony with the function of the building and also the theme of high tech architecture. The concept of micro land arrangement uses a supporting character that aims to create a land structure that supports building functions. The concept of micro shapes uses iconic characters that aim to create formations that can become markers of an area and have a vision for the future. The concept of space uses split-level characters that aim to create a continuous space that is like no limits, and provides easy and flexible access, because buildings have various spatial functions. All of these are intended to provide solutions to existing problems and refer to the need to provide an image of a future building.
\end{abstract}

Keywords: electric automobile, High Tech Architecture; future oriented

\begin{abstract}
Abstrak. Surabaya sebagai kota metropolitan membutuhkan solusi permasalahan polusi udara. Penggunaan transportasi listrik sangat mempengaruhi upaya mengurangi polusi udara akibat transportasi konvensional sehingga memberikan dampak yang baik bagi lingkungan. Terkait upaya pengurangan polusi udara akibat transportasi konvensional, maka Perancangan Gedung Futura Mega Electric Automobile di Surabaya yang merupakan bangunan dengan fungsi bisnis, edukasi dan rekreasi sebagai persiapan untuk menyambut kemajuan teknologi transportasi masa depan dan sebagai langkah awal untuk memperkenalkan teknologi transportasi listrik merupakan salah satu gagasan yang sangat menarik. Rancangan High Tech Architecture pada bangunan ini terinspirasi dari bangun mobil listrik yang berorientasi ke masa depan. Perancangan arsitektur bangunan dilakukan melalui serangkaian tahapan mulai dari identifikasi proyek, studi preseden, program rancangan, konsep hingga pengembangan rancangan. Makro konsep future oriented dipilih berdasarkan korelasi antara judul, fungsi bangunan dan tema sehingga diharapkan dapat memberikan citra bangunan yang berorientasi ke masa depan, selaras dengan fungsi bangunan dan juga tema high tech architecture. Konsep mikro tata lahan menggunakan karakter supporting yang bertujuan untuk menciptakan tatanan lahan yang mendukung fungsi bangunan. Konsep mikro bentuk menggunakan karakter iconic yang bertujuan untuk menciptakan bentukan yang dapat menjadi ikon penanda suatu wilayah dan bervisi ke masa depan. Konsep ruang menggunakan karakter split level yang bertujuan untuk menciptakan ruang kontinyu yang seperti tanpa batas, dan memberikan akses yang mudah dan fleksibel, dikarenakan bangunan memiliki fungsi ruang yang bermacam-macam. Semua hal tersebut dimaksudkan untuk memberikan penyelesaian terhadap permasalahan yang ada dan merujuk kepada kebutuhan untuk memberikan citra bangunan masa depan.
\end{abstract}

Kata Kunci: electric automobile, High Tech Architecture; future oriented 


\section{Pendahuluan}

Perancangan bangunan Gedung Futura Mega Electric Automobile di Surabaya, dilatarbelakangi adanya perkembangan teknologi transportasi begitu pesat yang tak terelakkan. Hal itu menyebabkan manusia harus mulai beradaptasi dengan perkembangan tersebut. Namun Indonesia yang merupakan negara berkembang, cenderung lebih lama untuk beradaptasi dan mengikuti zaman sehingga hanya mengandalkan teknologi konvensional yang menggunakan fosil, gas alam, dan juga pembangkit listrik yang mayoritas memanfaatkan bahan bakar batu bara sebagai penghasil listrik karena dinilai murah namun juga memiliki dampak yang buruk terhadap lingkungan dan ekosistem. Berdasarkan data dari Air Visual Air Quality Index (AQI) Kota Jakarta masuk kategori tidak sehat atau termasuk peringkat ketiga udara terburuk di dunia. Tidak dapat dipungkiri bahwa kota-kota lain seperti Kota Surabaya juga dapat menyusul nasib buruk dari Kota Jakarta.

Upaya pemerintah untuk mengurangi polusi udara adalah dengan cara memperkenalkan kepada masyarakat mengenai Electric Vehicle dengan diterbitkannya Perpres No. 55 Tahun 2019 tentang Percepatan Program Kendaraan Bermotor Listrik Berbasis Baterai (Battery Electric Vehicle) untuk Transportasi Jalan agar masyarakat dapat segera beralih dari kendaraan yang menggunakan bahan bakar fosil yang memiliki tingkat emisi gas buang yang cukup tinggi ke teknologi yang ramah lingkungan yaitu dengan tenaga listrik. Namun $E V$ ini sendiri memerlukan riset dan juga infrastruktur yang memadai dikarenakan berbeda dengan BBM yang cepat proses pengisiannnya, EV memerlukan waktu untuk pengisian battery layaknya mengisi battery smartphone, dan juga membutuhkan Charging Station, sehingga membutuhkan persiapan dan juga waktu yang cukup lama sebelum bisa dikonsumsi publik. Sehingga diperlukan wadah untuk memperkenalkan $E V$ ini kepada khalayak luas guna memberikan wawasan bahwa $E V$ ini sendiri tidak buruk seperti isu-isu yang telah beredar. Langkah awal untuk memperkenalkan teknologi ini melalui pameran-pameran yang diselenggarakan oleh pihak APM itu sendiri. Diharapkan dengan adanya Futura Mega Electric Automobile masyarakat dapat lebih mengenal teknologi dan produk dari Electric Vehicle dan beralih dari kendaraan BBM ke Electric Vehicle sehingga berdampak baik pada udara Kota Surabaya yang merupakan kota metropolitan kedua terbesar setelah Kota Jakarta. Selain itu dapat menjadi sarana bisnis, edukasi sekaligus rekreasi bagi masyarakat urban yang membutuhkan bangunan yang mengusung konsep One Stop System.

Latar belakang tersebut menimbulkan sebuah permasalahan perancangan adalah bagaimana menciptakan sarana bisnis, edukasi dan rekreasi terpadu dalam satu bangunan gedung. Juga bagaimana cara memperkenalkan teknologi mobil listrik yang mudah dan tidak membosankan bagi masyarakat Surabaya, khususnya di lokasi Jalan Mayjend. Yono Suwoyo, Kelurahan Dukuh Pakis, Kecamatan Wiyung, Kota Surabaya, Jawa Timur, yang merupakan kawasan bisnis. Sehingga dipilihlah suatu tapak di Jalan Mayjend. Yono Suwoyo, yang memiliki batas Utara : Hartono Bukit Darmo, Timur : Jalan Mayjen Yono Suwoyo dan Mall Lenmarc, Selatan : Lahan kosong, Barat : Lahan Kosong dan pemukiman.

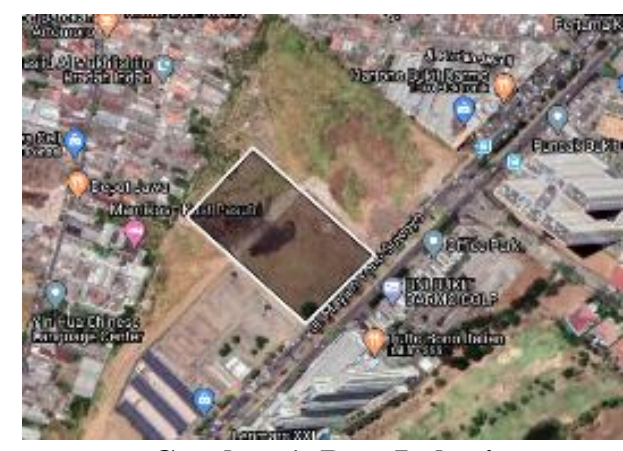

Gambar 1. Peta Lokasi

\section{Kajian Pustaka}

Arsitektur high tech merupakan langgam yang menggambarkan semangat modern dan teknologi yang ditampilkan dalam bentuk kejujuran struktur, permainan warna, penggunaan teknologi terbaru dalam struktur bangunan, serta mempunyai beberapa keunikan, dan pemecahan masalah, yang kemudian diimplementasikan dalam perancangan bangunan. Tema high tech nantinya didukung dengan konsep makro berupa future oriented sehingga didapatkan sebuah konsep bangunan gedung yang mewadahi fasilitas mobil listrik dengan desain yang berorientasi ke masa depan. 


\subsection{Pengertian Judul}

Futura diambil dari kata "Future" yang merupakan arti dari masa depan, sehingga penamaan ini sendiri merupakan representasi akan bangunan ini nantinya. Mega sendiri memiliki arti sebagai besar/luas bertujuan agar dapat mencakup lingkup yang cukup luas (Kamus Besar Bahasa Indonesia). Electric Vehicle dalah kendaraan yang menggunakan satu atau lebih motor listrik atau motor traksi sebagai tenaga penggeraknya. Automobile sendiri merupakan istilah Secara khusus, "otomatis" berarti "dari dirinya sendiri" dan mengacu pada sesuatu yang dapat beroperasi sendiri tanpa bantuan eksternal. Transmisi otomatis menggerakan sendiri. Sedangkan "Mobile" berarti "mampu bergerak". Entah didorong, ditarik, dll. Oleh karena itu, "automobile" berarti kendaraan yang memiliki kemampuan untuk bergerak tanpa bantuan daya eksternal.

Berdasarkan beberapa uraian pengertian di atas, maka pengertian dari judul "Arsitektur High Tech pada Rancangan Gedung Futura Mega Electric Automobile di Surabaya" adalah suatu rancangan bangunan gedung terpadu yang di dalamnya terdapat fasilitas berupa showroom, theme park, dealer dan bengkel, sirkuit test drive, cafe \& lounge, musholla, pusat informasi, pelayanan publik, ruang keamanan, tempat parkir dan yang lainnya dan dikemas secara terpadu. Sebagai wadah untuk memperkenalkan teknologi transportasi masa depan bagi masyarakat urban dan sebagai sarana berbelanja kebutuhan mobil listrik maupun edukasi.

\subsection{Studi Preseden}

Studi preseden atau studi banding merupakan suatu kegiatan yang dilakukan dengan cara menentukan objek atau lokasi sebagai pembanding terhadap apa yang diketahui oleh pengamat untuk dilakukan tinjauan dengan tujuan mendapatkan informasi yang menjadi referensi perancangan bangunan. Studi ini dilakukan dengan cara studi banding lapangan dan studi banding literatur.

Studi banding lapangan merupakan kegiatan meninjau suatu objek secara langsung di lokasi untuk mengetahui bagaimana keadaan dan kondisi objek yang sebenarnya. Penulis melakukan studi banding lapangan terkait judul Gedung Futura Mega Electric Automobile dengan mengadakan tinjauan lapangan sehingga diperoleh gambaran beberapa fasilitas terkait judul seperti Gallery, Dealer \& Showroom. Berikut beberapa studi banding lapangan yang dipilih dari beberapa obyek: (1) Indonesia International Motor Show 2019 (Studi Terkait Gallery / Pameran) Grand City Convex Surabaya. (2) Museum Angkut Batu (Studi Terkait Gallery pada Museum Angkut) Jl. Terusan Sultan Agung No.2, Kota Batu, Jawa Timur. (3) Porsche Centre Surabaya (Studi Terkait Dealer \& Showroom) Jl. Adityawarman No.41, Kota Surabaya. (4) Eurokars Mazda Adityawarman (Studi Terkait Dealer \& Showroom) Jl. Adityawarman No.23, Kota Surabaya.

Studi banding literatur adalah kegiatan mempelajari suatu objek untuk memperoleh data yang bersumber dari pustaka berupa buku, majalah, atau artikel di internet yang akurat dan terpercaya. Penulis mengadakan studi banding literatur terkait judul untuk melengkapi kekurangan yang didapat dari studi lapangan, dan juga studi literatur terkait tema High Tech Architecture. Objek untuk studi literatur yang dipilih adalah: (1) Ferrari World Abu Dhabi by Benoy (Studi Terkait Tema High Tech, Galeri dan bangunan Automobile). (2) Renault Distribution Centre by Norman Foster (Studi Terkait Galeri dan Tema High Tech).

Dari beberapa studi kasus diatas, kemudian di analisa dan diambil kesimpulan, Tabel 1 berikut beberapa kelebihan dan kekurangan:

Tabel 1. Studi Preseden pada Beberapa Obyek Kasus

\begin{tabular}{|lll|}
\hline No. & \multicolumn{1}{c|}{ Kelebihan } & \multicolumn{1}{c|}{ Kekurangan } \\
\hline 1 & $\begin{array}{l}\text { IIMS Surabaya memiliki format layout booth dengan } \\
\text { sirkulasi yang mudah. }\end{array}$ & $\begin{array}{l}\text { Tidak meratanya tempat penataan booth membuat bagian } \\
\text { pojok cenderung sepi dan jarang dikunjungi. } \\
\text { Museum Angkut memiliki konsep dan tema yang } \\
\text { Penghawaan dan pencahayaan yang cenderung kurang } \\
\text { baik, sehingga pengunjung kurang nyaman. }\end{array}$ \\
& $\begin{array}{l}\text { koleksi yang ada didalamnya. } \\
\text { Porsche Centre memiliki sistem selubung, struktur, } \\
\text { interior dan utilitas yang mumpuni. Citra bangunan } \\
\text { automobile yang modern dan fungsional dapat terlihat } \\
\text { dari fasad depan dan sistem bangunannya. }\end{array}$ & \\
\end{tabular}




\begin{tabular}{|lll|}
\hline No. & \multicolumn{1}{c|}{ Kelebihan } & \multicolumn{1}{c|}{ Kekurangan } \\
\hline 4 & $\begin{array}{l}\text { Mazda Adityawarman memiliki pembagian zona kantor } \\
\text { layanan yang berbeda lantai dengan dealer sehingga } \\
\text { memberikan kesan yang formal pada kantor. }\end{array}$ & $\begin{array}{l}\text { Tidak terdapat tangga darurat pada bangunan membuat } \\
\text { keamanan yang kurang, dan area yang tidak terbangun } \\
\text { minim, sehingga alur sirkulasi dan parkir menjadi kacau } \\
\text { dan terkesan sempit }\end{array}$ \\
5 & $\begin{array}{l}\text { Ferrari World memiliki bentuk yang otentik dan } \\
\text { menggunakan sistem bangunan berteknologi tinggi }\end{array}$ & $\begin{array}{l}\text { Pengaplikasian yang sulit dan biaya proyek yang mahal } \\
\text { Renault centre memperlihatkan kecanggihan material } \\
\text { dan pengaplikasian struktur yang rumit menjadi suatu } \\
\text { karya arsitektural yang estetik, dan dikemas dengan tema } \\
\text { high tech. }\end{array}$ \\
\hline
\end{tabular}

\section{Metode Penelitian}

Penelitian ini menggunakan metode deskriptif dan studi kasus. Pengumpulan data dan informasi dilakukan melalui kegiatan observasi objek studi untuk mendapatkan referensi berdasarkan fakta-fakta dan isu-isu yang ada. Kemudian dilakukan wawancara secara formal maupun informal kepada narasumber yang memiliki pengetahuan terkait objek studi untuk mendapatkan informasi tambahan atau bukti yang memperkuat informasi yang telah diperoleh. Selanjutnya data tersebut diolah, dianalisis dan dibuat sintesis berupa konsep sebagai acuan rancangan bangunan. Metode deskriptif digunakan sebagai pemecahan masalah yang diselidiki dengan menggambarkan keadaan objek bangunan berdasarkan fakta-fakta yang tampak secara apa adanya. Sedangkan studi kasus digunakan untuk memberikan gambaran lengkap obyek yang pada umumnya dilakukan melalui pengamatan studi literatur yang didapat dari beberapa media seperti buku, jurnal arsitektur, hingga website guna memperoleh data dan informasi tambahan. Penelitian untuk perancangan dalam hal ini adalah guna memperoleh data dan informasi untuk kebutuhan perancangan, sehingga rancangan bisa mengakomodasikan kebutuhan yang sebenarnya dari pengguna.

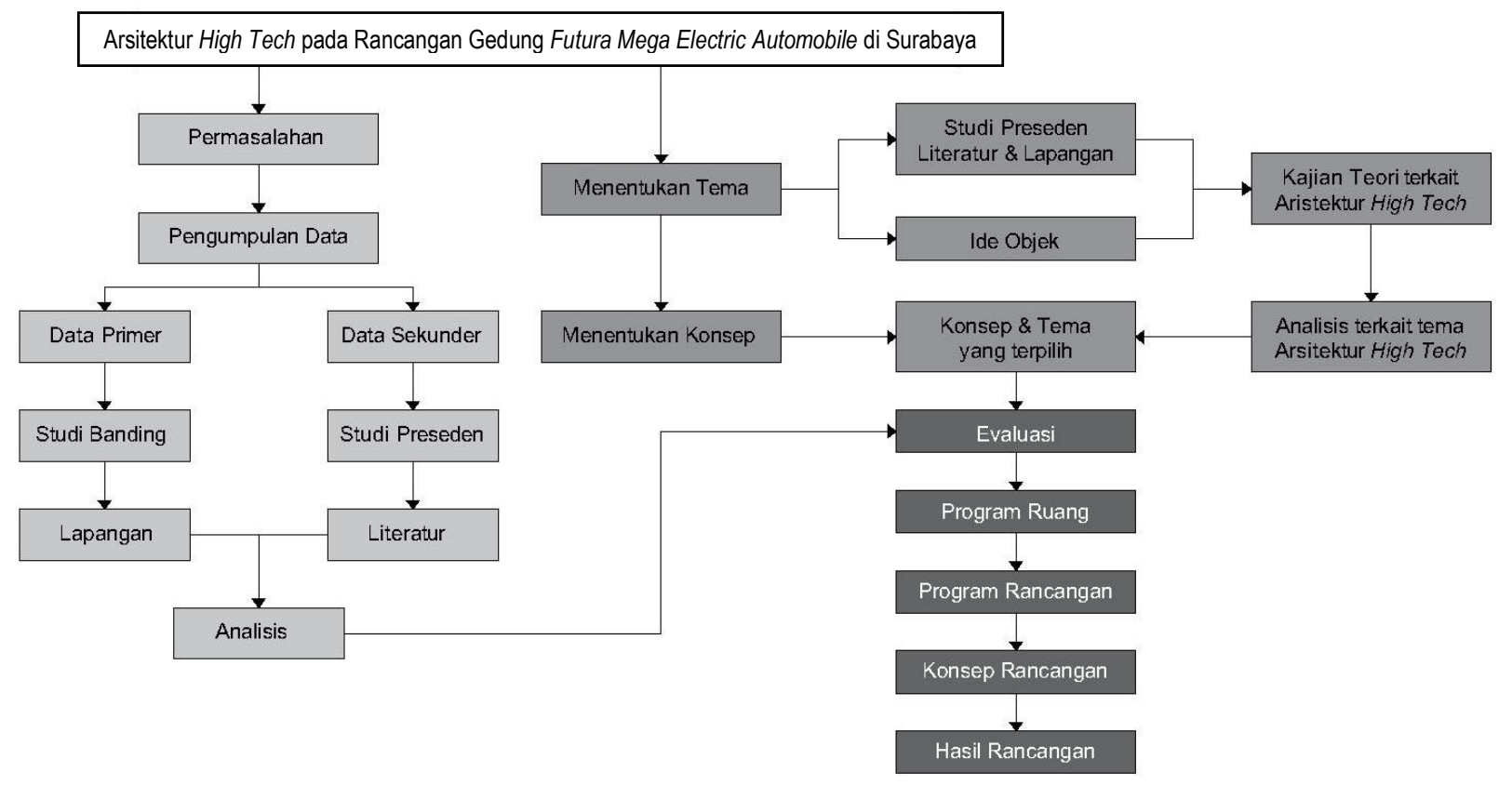

Gambar 2. Diagram Metode Penelitian

\section{Hasil dan Pembahasan}

Berdasarkan hasil analisis dan program rancangan maka diperoleh konsep makro dengan dua kata kunci yakni future dan oriented yang dimana arti kata future dalam bahasa inggris yang berarti masa depan sedangkan oriented yang berarti orientasi, sehingga jika kedua kata tersebut digabungkan, maka terciptalah future oriented yang berarti berorientasi ke masa depan. Berdasrkan konsep ini, maka arah rancangan diharapkan dapat menjadi sebuah wadah untuk memperkenalkan teknologi transportasi masa depan kepada masyarakat Surabaya. 


\subsection{Tema sebagai pendekatan desain}

Pendekatan Arsitektur high tech pada rancangan dapat terlihat dari luar bangunan, seperti fasad, hingga utilitas dan struktur bangunan yang diekspos, guna memenuhi ciri khas arsitektur high tech, yakni smart building terutama pada utilitasnya. Selain itu pendekatan arsitektur high tech juga ditampilkan dalam warna abu-abu glossy dan material berteknologi tinggi seperti kalzip, kaca low e, hingga kaca photovoltaic, dan sebagainya.

\subsection{Program Ruang}

Merupakan tahapan penyusunan kebutuhan ruang berdasarkan hasil yang telah didapat pada studi banding sehingga dapat menjadi referensi dan kemudian di aplikasikan kepada pemrograman ruang, seperti metode penyusunan ruang, jenis ruang, besaran ruang, organisasi ruang, diagram hubungan ruang, dan persyaratan ruang.

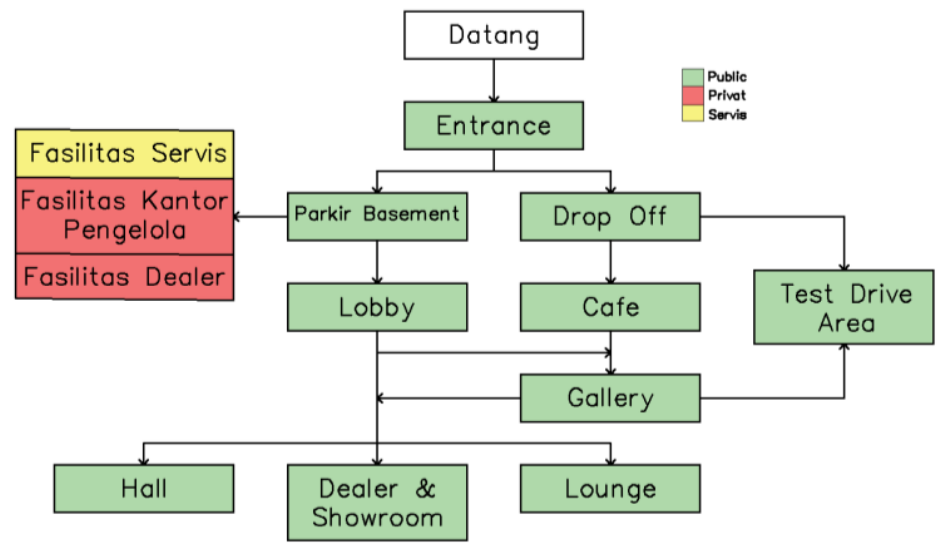

Gambar 3. Organisasi ruang makro

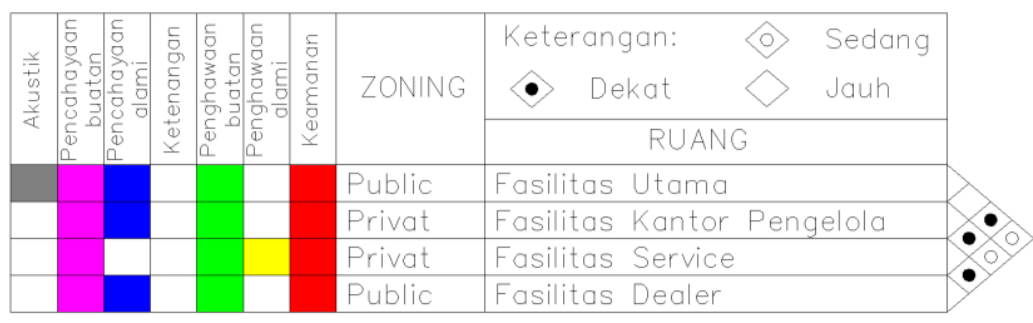

Gambar 4. Hubungan ruang makro

\subsection{Konsep dan Transformasi}

Berdasarkan judul dan tema, ditentukanlah konsep perancangan mulai dari makro konsep hingga mikro konsep, yang kemudian diaplikasikan pada desain rancangan melalui tahap transformasi berupa tatanan lahan, bentuk dan ruang. 
Judul :

Arsitektur High Tech pada Perancangan Gedung Futura Mega Electric Automobile di Surabaya

Makro Konsep : Future Oriented

Future adalah masa yang akan datang dan Oriented adalah mengarahkan, sehingga nantinya bangunan akan memberikan kesan yang berorientasi ke masa depan.

Mikro Konsep Tatanan Lahan : Supporting

Supporting adalah Mendukung, sehingga nantinya akan bersifat mendukung bangunan.

Menciptakan tatanan lahan yang mendukung fungsi bangunan, dimana tatanan lahan tidak terlalu menonjol sehingga masa bangunan dapat menjadi focus dan point interest pada site dan menampilkan citra bangunan yang ikonik, megah dan eksklusif. Sebagai persiapan untuk menyambut kemajuan teknologi transportasi masa depan.

\section{$\checkmark$}

Mikro Konsep Bentuk : Iconic

Iconic adalah sesuatu yang memunculkan gambaran dalam pikiran dengan mudah.

Menciptakan bentukan yang ikonik dan berfisi ke masa depan, sesuai dengan tema dan judul, sehingga dapat menarik perhatian masyarakat dan dapat menjadi suatu ikon atau landmark Kota Surabaya

Mikro Konsep Ruang : Split Level

Menciptakan ruang yang seperti tanpa batas, dan memberikan akses yang mudah dan fleksibel, dikarenakan bangunan memiliki fungsi ruang yang bermacam - macam, seperti ruang privat pada office hingga ruang dealer dan showroom vang bersifat umum.

\section{Gambar 5. Diagram konsep rancangan}

\section{a. Rancangan Tatanan Lahan}

Pada konsep mikro tata lahan menggunakan konsep Supporting yang berarti menciptakan tatanan lahan yang mendukung fungsi bangunan, sehingga tatanan lahan dibuat agar dapat mencakup kebutuhan bangunan. Beberapa kebutuhan seperti sirkuit dan test drive area, charging station, parkir motor, hingga beberapa taman sebagai fasilitas penunjang yang ditujukan selain untuk menarik perhatian pengunjungdan kenyamanan, namun juga sebagai sarana edukasi dan rekreasi.


Gambar 6. Area penunjang pada site

Area sirkuit difungsikan sebagai sarana edukasi dan rekreasi, dimana sirkuit ini sendiri juga menjadi nilai tambah pada bangunan, sehingga dapat menarik perhatian pengunjung. Area sirkuit ini sendiri didesain sedemikian rupa sebagai tempat untuk para pengunjung yang ingin merasakan rasa berkendara menggunakan mobil listrik, maupun menikmati atraksi - atraksi yang menggunakan stuntman yang disediakan oleh pengelola untuk menghibur pengunjung. Terdapat jembatan pada sirkuit yang dapat difungsikan bagi pengunjung untuk melihat lintasan dari ketinggian yang berbeda, sehingga 
pengunjung memiliki opsi untuk menikmati view lintasan melalui jembatan atau viewing area yang sudah disediakan.

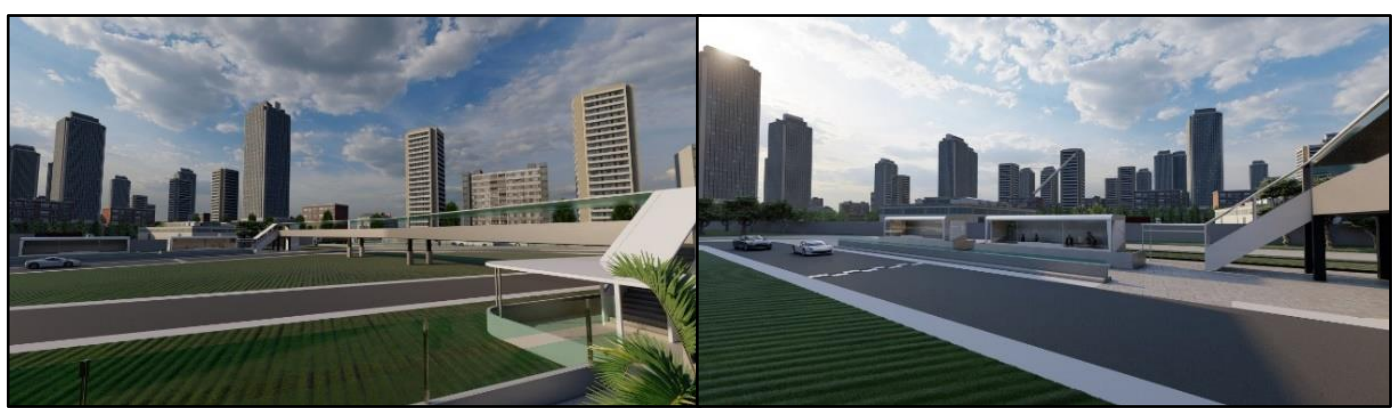

(a)

(b)

\section{b. Rancangan Bentuk}

Gambar 7. a) Jembatan pada sirkuit; b) Viewing Area

Pada konsep mikro bentuk pemilihan konsep ikonik dinilai mampu memberikan citra bangunan yang unik dan mudah dikenali sehingga dapat menciptakan bentukan yang berfisi ke masa depan, sesuai dengan tema dan fungsi bangunan, sehingga dapat menarik perhatian masyarakat dan dapat menjadi suatu ikon atau landmark di Kota Surabaya. Bentukan diambil dari proporsi mobil coupe yang kemudian di realisasikan kedalam desain dengan menggunakan metafora secara intangible guna memberikan kesan bangunan automobile yang kuat.

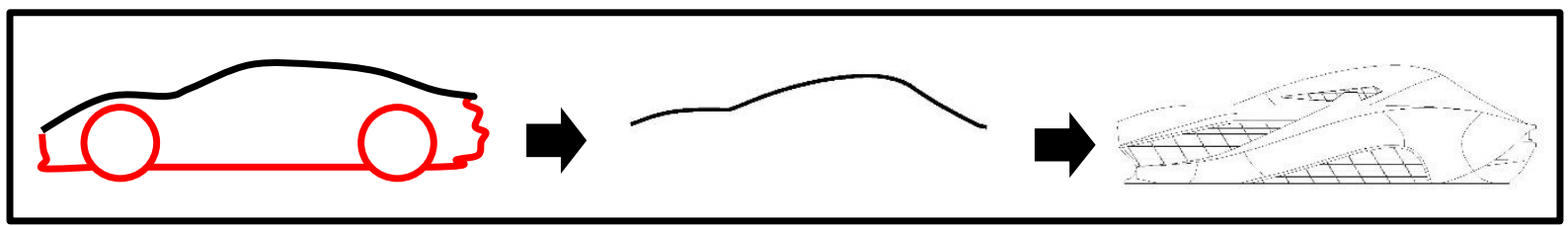

Gambar 8. Transformasi Bentuk

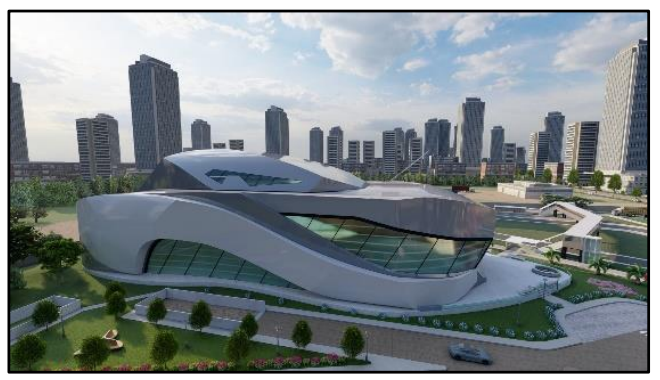

(a)

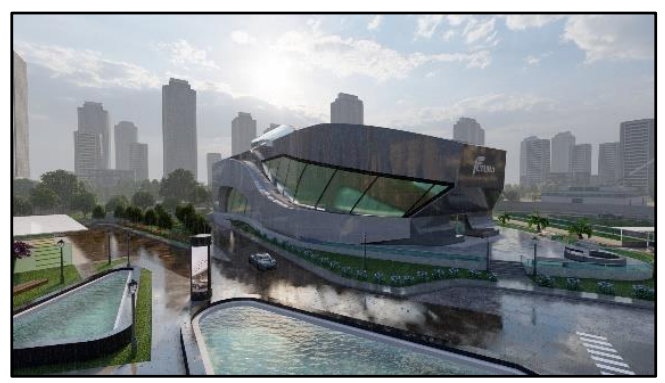

(b)

Gambar 9. a) 3D Tampak samping bangunan, b) Bentuk akhir bangunan

\section{c. Rancangan Ruang}

Pada konsep mikro ruang menggunakan konsep split level yang bertujuan menciptakan ruang seperti tanpa batas, dan memberikan akses yang mudah dan fleksibel, dikarenakan bangunan memiliki fungsi ruang yang bermacam - macam, seperti ruang privat pada office hingga ruang dealer dan showroom yang bersifat umum. Konsep ruang split level sendiri memungkinkan space yang lebih banyak dan memberikan pola elevasi yang tidak monoton, hal ini baik untuk pengunjung agar tidak mudah bosan dan lebih menikmati rasa perjalanan sewaktu mengakses fasilitas didalamnya. 

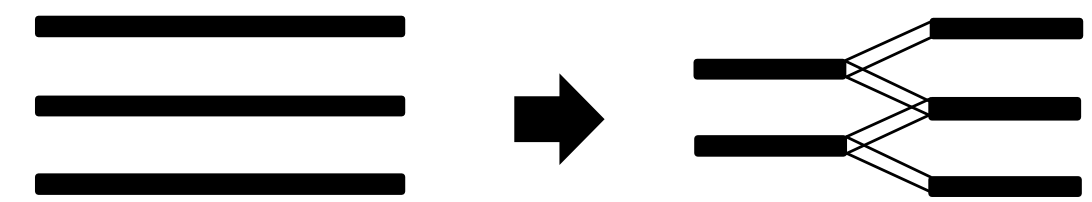

Gambar 10. Transformasi Ruang

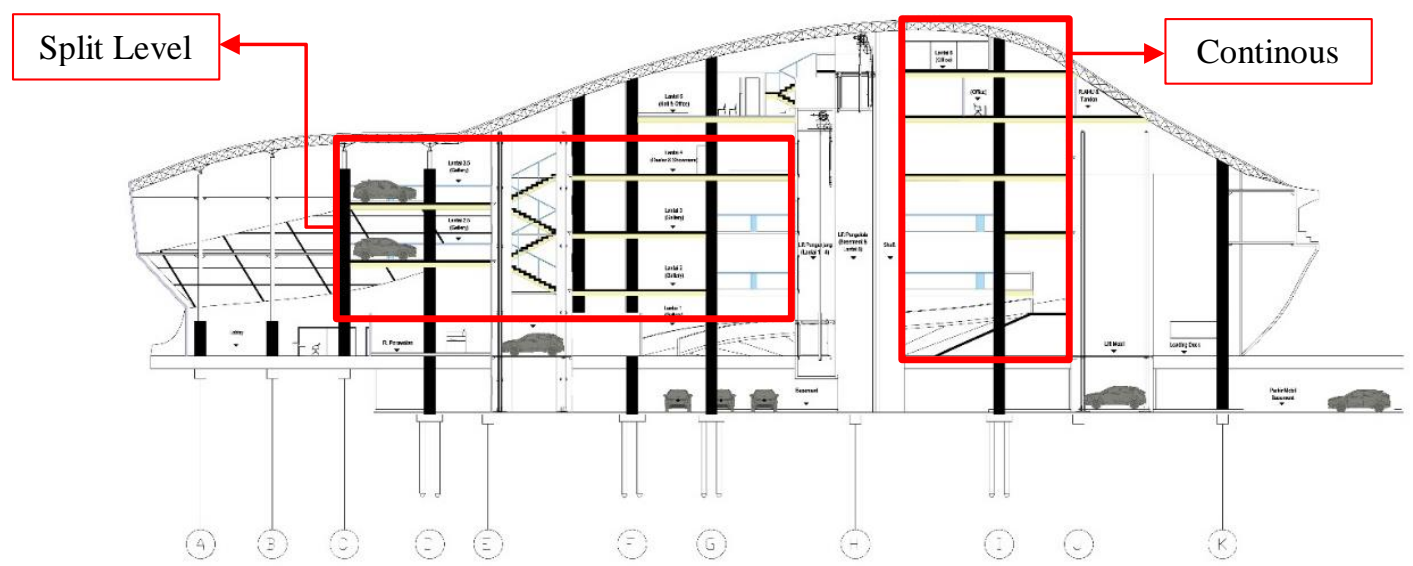

Gambar 11. Penerapan konsep ruang split level pada potongan bangunan

\section{d. Rancangan Sistem Bangunan}

Struktur pada bangunan menggunakan kolom baja dan diliapisi cor guna memberikan kekuatan yang lebih baik untuk menopang beban axial yang didapat pada lantai split level, pada ruang tengah yang difungsikan untuk utilitas bangunan, dinding yang digunakan merupakan shear wall, guna sebagai pengaku untuk beban lateral, maupun menopang beban axial pada tiap lantai.



Gambar 12. Sistem struktur pada bangunan

Strukur atap sendiri menggunakan struktur space frame, hal ini dikarenakan bentukan atap yang memiliki lekukan yang banyak, sehingga space frame merupakan opsi yang baik, dan sistem struktur spaceframe sendiri merupakan sistem struktur teknologi tinggi yang disematkan pada bangunan. 


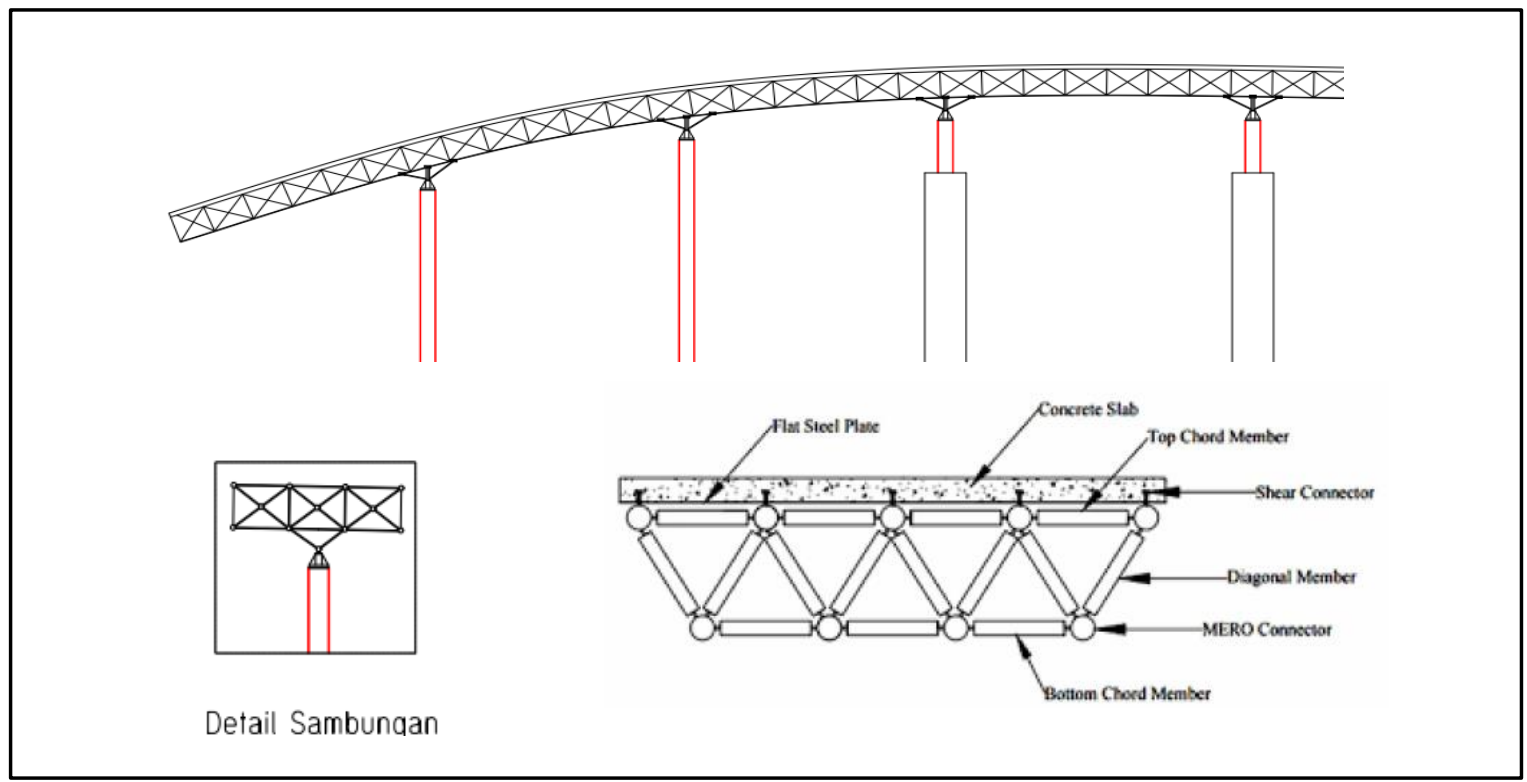

Gambar 13. Sistem struktur atap

Sistem distribusi listrik, merupakan aspek penting yang harus diperhatikan pada bangunan high technology, hal ini dikarenakan daya yang dibutuhkan cukup tinggi, sehingga tanggapan desain terkait distribusi listrik adalah memberikan solar panel pada parkiran sepeda motor dan juga penggunaan kaca photovoltaic yang disematkan pada selubung bangunan.

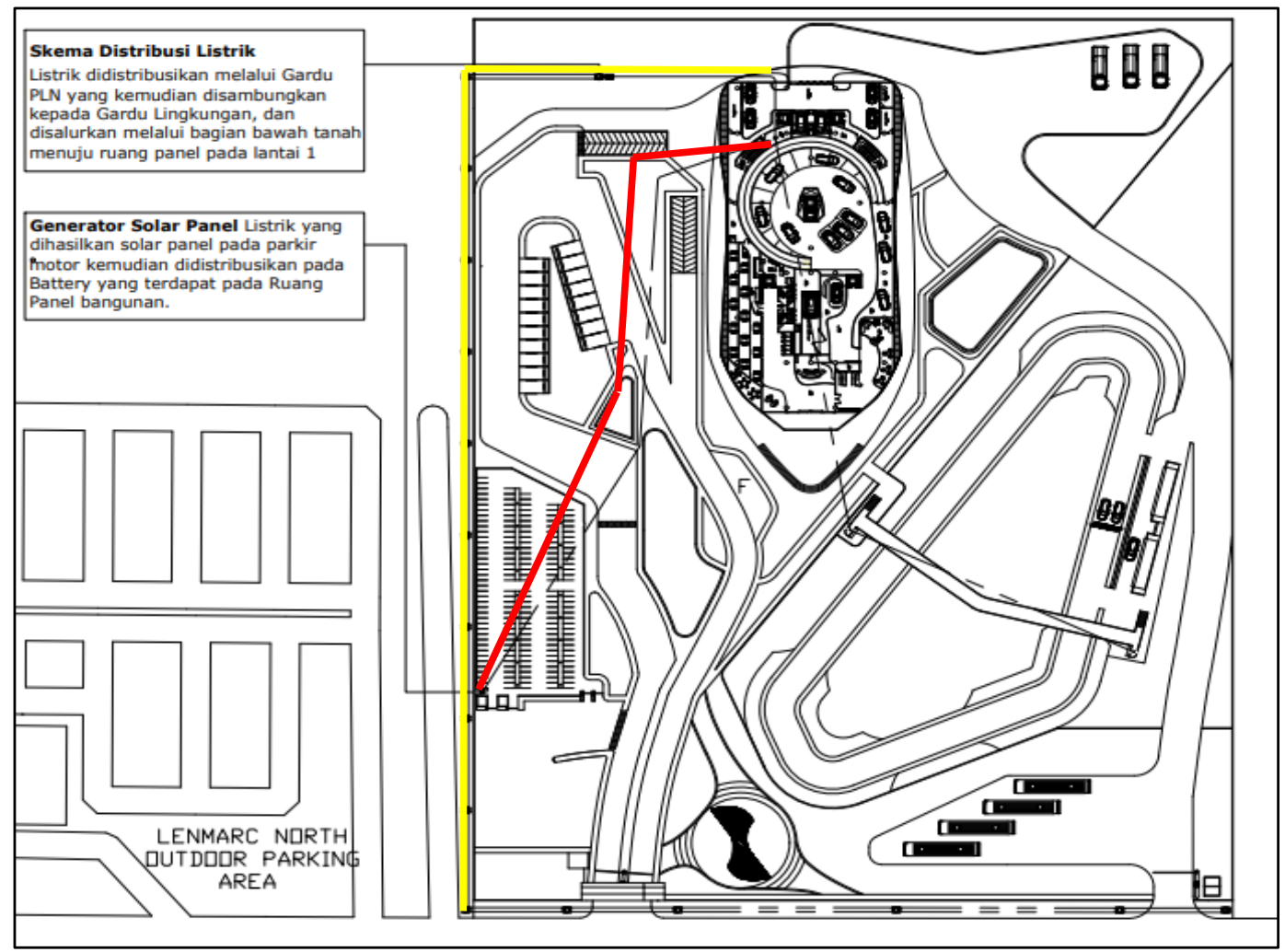

Gambar 14. Distribusi listrik pada site

Selain solar panel pada parkiran sepeda motor upaya meminimalkan beban, pada bagian kaca bangunan juga disematkan material kaca yang berteknologi tinggi, dengan kombinasi antara kaca lowe-glass dan kaca photovoltaic dapat membantu mereduksi radiasi yang dihasilkan panas matahari, sekaligus menyimpan energi, yang nantinya digunakan untuk membantu suplai daya pada bangunan. 


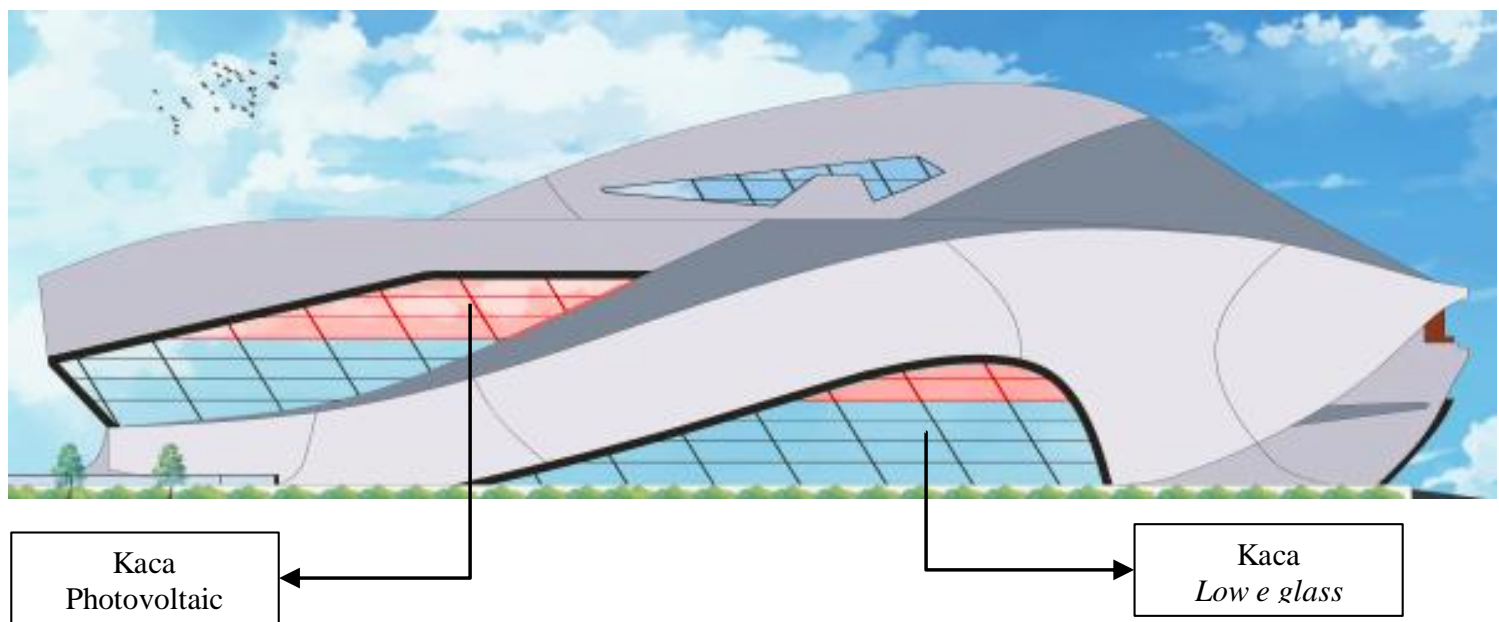

Gambar 15. Penyematan teknologi tinggi pada selubung bangunan

\section{Kesimpulan}

Arsitektur High Tech pada Rancangan Gedung Futura Mega Electric Automobile di Surabaya ini diharapkan dapat menjadi ikon Kota Surabaya sekaligus wadah untuk memperkenalkan teknologi transportasi masa depan yang berbasis energi listrik. Tujuannya adalah memberikan wawasan baru kepada masyarakat agar beralih menggunakan teknologi transportasi masa depan yang ramah lingkungan dan berdampak kepada pengurangan emisi gas buang sehingga dapat memberikan udara yang sehat pada Kota Surabaya. Selain itu dari segi desain bentuk rancangan memberikan sudut pandang lain terhadap bentukan bangunan pada umumnya, sehingga memberikan citra dan identitas banguna $\mathrm{n}$ automobile dan tema high tech yang kuat, dimana terdapat penyematan teknologi tinggi yang ramah lingkungan pada bangunan guna membantu mereduksi kebutuhan energi fosil yang non renewable. Penataan ruang luar ditujukan untuk mendukung fungsi bangunan, sehingga pada bagian ruang luar terdapat beberapa taman dan fasilitas yang dapat digunakan pengunjung secara lebih optimal. Gedung ini juga diharapkan dapat memenuhi kebutuhan masyarakat akan sarana bisnis, edukasi dan rekreasi. Pendekatan tema high tech serta konsep future oriented merupakan alternatip solusi terhadap permasalah perancangan bangunan dalam mengantisipasi perkembangan jaman.

\section{Referensi}

Energy Efficiency \& Renewable Energy. (2020). Electric Vehicle Basics. Washingon, DC: U.S. Department of Energy. [Diakses dari: https://www.energy.gov/eere/electricvehicles/electricvehicle-basics. 26 Juli 2020] .

Jenks, Charles (1988). The Battle of High Tech and Great Buildings with Great Faults, Architectural Design

Media Matrasin Vol. 8, No. 2 Agustus 2011. [Diakses dari: https://docplayer.info/48897289-Mediamatrasain-vol-8-no-2-agustus-2011.html]

Sistrunk, Bill (2017). What is an automobile?. [Diakses dari: https://www.quora.com/What-is-anautomobile. 26 Juli 2020]. 